\title{
Upper Palaeolithic and Late Stone Age Human Diet
}

\author{
Maria V. Dobrovolskaya \\ Institute of Archaeology of Russian Academy of Sciences, Moscow, Russia
}

\begin{abstract}
Undoubtedly modern mankind is an omnivorous species. Nevertheless, types of diet changed at the time of anthropogenesis. The Upper Palaeolithic period is the crucial time because of the appearance of anatomically modern humans in Europe. The main goal in this period investigation is to find the Neanderthal man-Upper Palaeolithic man diet distinction. A sharp early Holocene rise in humidity and temperature and melting of the permafrost resulted in the complete destruction of traditional migration routes, campsite losses, and the flora and fauna of inland territories changing. All these factors affected nutrition patterns, too. The comparison of the different Mesolithic and Neolithic groups' diet patterns allow us to discuss problems of the influence of cultural and ecological factors. The bone tissue chemical concentrations ( $\mathrm{Ca}, \mathrm{Zn}, \mathrm{Sr}, \mathrm{Cu})$ from Upper Palaeolithic, Mesolithic and Neolithic burials are considered to reconstruct individual and group patterns of nutrition. The results of the atomic absorption method were used. J Physiol Anthropol Appl Human Sci 24(4): 433-438, 2005 http://www.jstage.jst.go.jp/ browse/jpa
\end{abstract}

[DOI: 10.2114/jpa.24.433]

Keywords: human evolution, Upper Palaeolithic, diet, bone mineral content

\section{Introduction}

Undoubtedly, modern mankind is an omnivorous species. Nevertheless types of diet changed at the time of anthropogenesis. First of all, the appearance of the genus Homo is connected with the herbivore-omnivore transition. It is well known that most primate species are herbivores. They feed on leaves, flowers, fruits, and other parts of plants. A few species of anthropomorphic primates live on animal proteins. According to Foley (1984), the early stages of anthropogenesis were connected with diet structure change and the increase of animal proteins as part of everyday nutrition. This point was the basis for the progressive development of brain structures. The role of hunting for Australopitecus, Homo erectus, and Homo sapiens neandertalensis has been discussed from different aspects (Foley, 1984; Brantingham, 1998; Bocherens,
1997). This investigation is dedicated to the reconstruction of the main nutrition patterns of the Upper Palaeolithic and Mesolithic human populations. The diet type is a variant of social adaptation on the one hand. The ration of the proteinscarbohydrates - fats affects body build, growth and pubescence rates and others on the other hand. On the basis of the paleodiet data we can reconstruct social and ecological aspects of the concrete prehistoric communities' adaptation.

The Upper Palaeolithic period is the crucial time because of the appearance of the anatomically modern human in Europe. The main goal of this period investigation is to find the Neanderthal man-Upper Palaeolithic man diet distinction. Stable isotopic investigation results confirm carnivore specialization of the Neanderthal population (Bocherens, 1997). Detailed consideration of the Sunghir' Upper Palaeolithic samples will make it possible to reconstruct the diet of this group and of Upper Palaeolithic Europe inhabitants in general.

The sharp early Holocene rise in humidity and temperature and the melting of permafrost resulted in the complete destruction of traditional migration routes, campsite losses, and the flora and fauna of inland territories changing. All these factors affected nutrition patterns too. The general rise of the World Ocean level must have affected the coastal sites, many of which were submerged. Nevertheless the inhabitants of the coastal sites did not change their ecological niche and the main patterns of their lifestyle. This is unambiguously demonstrated by the comparison of diet types of the final Upper Palaeolithic and Neolithic people buried at Arene Candide, northern Italy (Francalacci, 1989). The comparison of the different Mesolithic and Neolithic groups diet patterns lets us discuss problems of the influences of cultural and ecological factors.

\section{Methods}

Modern anthropology uses several methods of ancient human diet reconstruction. The most commonly used is stable isotope analysis. Bone tissue concentration of ${ }^{15} \mathrm{~N}$ and ${ }^{13} \mathrm{C}$ are using for revealing the land and marine food components, animal and plant food, C3 and C4 photosynthesis plant food and some other patterns of nutrition (Ambrose, 1993). Trace element analysis is used for palaeodiet reconstruction, too 
(Kozlovskaya, 2000a). Concentrations of the strontium, calcium, zinc and copper are used for palaeodiet reconstructions.

All fragments of bone tissue were removed from the external compact layer as mostly susceptible to contamination. The samples were washed with distilled water, dried in the exsicator, and checked for reduction to an absolute dry weight. After being weighed, bone tissue fragments were placed in 20 millilitres of $1 \mathrm{~N}$ solution of hydrochloric acid where they stayed from 3 to 5 days, depending on the demineralisation rate, being shaken up every 24 hours. Then the solution was filtered; the organic residuum was dried and weighed. The concentrations of chemical elements were estimated in received filtrates by the atomic absorption technique, which has been successfully used in many such studies.

For the estimations, the 180-80 model of the "Hitachi" Atomic Absorption Spectrometer was used with the Zeeman effect in an air-acetylene flame, and for strontium in a nitrous oxide-acetylene flame. The concentration values of copper, zinc, lead, cadmium, nickel, cobalt, manganese and strontium were estimated in the Laboratory of Atomic Absorption, Faculty of Geography, Moscow State University. The concentrations of calcium were estimated by the flame photometry technique in the Laboratory of Geochemistry of Landscapes, Faculty of Geography, Moscow Pedagogical State University.

The results of the analysis are given in the following tables. Mineral saturation was estimated as a percentage of a quotient of soluble mineral mass to the whole mass of a sample. Calcium concentration is given as a percentage of a sample mass, and concentrations of other elements in $\mathrm{ppm}$ $-1 \times 10^{-4} \%$. All the units are of standard use in international publications.

The data obtained testify to a different degree of bone tissue preservation in four skeletons. An extremely high percentage of mineralisation is typical for bone tissues of both adolescents (C2 and C3). Such values are much higher than they were in their real lifetime. The reason for such transformation lies, probably, in considerable diagenetic changes that took place after burial. Such results can hardly be thought unexpected. As a rule, maximal posthumous changes occur precisely in nonmatured bone structures where mineral concentration has not yet reached its final value, and mineral substances are in a more amorphous state than in adults, etc. Although the received figures cannot be used for the reconstruction of a person's lifetime mineralisation, it does not mean that the whole analysis may by of interest only from the viewpoint of the study of diagenetic processes. If the absolute values of the traits are questionable, their relative parameters can still be properly used.

Although we did not have sufficient opportunity to research bone postmortem transformations in detail, we can point out the relatively good preservation of the bone tissue, based on chemical and histological analysis. Traces of the carry-over are not found.

\section{Results}

The analysis of the Sunghir' skeletons notes the absence of any chemical element deficiency (Table 1). The moderate and low concentrations of the $\mathrm{Ca}$ were determined for individuals C-1, C-2 and C-4.

Male from burial 1 (Sunhgir 1). First, it should be noted that due to excellent bone preservation all of the received data should be considered as highly reliable. The mineral status of this individual in general should be characterised as normal, well balanced, and without any traces of age changes (Table 1). Most of this man's diet undoubtedly consisted of terrestrial vertebrate meat. Judging by trace element concentrations, this man at least in the latest years of his life did not experience prolonged malnutrition or any problems with food assimilation.

Adolescent from burial 2 (Sunghir 2, the boy). The mineralisation of bone tissue is very high, which testifies to considerable posthumous changes of tissue composition. These changes occurred, in the first place, in the organic part of the bone, which is why the data on the concentrations of trace elements should be regarded with a certain degree of caution; and to estimate the mineral status in general is not at all possible. The values of elements (nutritional indicators) show that the diet of this particular person was probably very different from that of the male from burial 1 (Table 1). The analysis of trace element concentrations helps to reconstruct an unexpected combination of a low proportion of meat, a large proportion of plants and a very high proportion of invertebrates in this adolescent's diet. Moreover, a low concentration of zinc in the skeleton gives good reason to suggest a clear quantitative insufficiency of animal protein food. It is also worth noting that this person's teeth are marked with multiple enamel hypoplasia, which may serve as evidence of several stresses, experienced in childhood. Those stresses could have been possibly connected with malnutrition, or food assimilation problems (Buzhilova, 2000).

Adolescent from burial 2 (C3, the girl). Very high mineralisation of this specimen hardly allows the description of a general characteristic of lifetime mineral status. Very high calcium concentrations give some reason to suggest that the process of bone tissue mineralisation deviated slightly from normal. Concentrations of the elements (nutritional indicators) are generally close to those determined for the male. However, the decrease in zinc concentration and the increase in strontium may be connected with some changes in the diet structure in terms of increase in vegetable food. Judging by the zinc level, nutrition was insufficient. The teeth of this individual also have multiple enamel defects, possibly connected with physiological stresses in early childhood.

Isolated femur (C-4). The bone preservation can be considered as satisfactory. The mineral status of this individual should be characterised, in the first place, as quite different from the three previously discussed cases. The skeleton of a person whose femur had been buried is less mineralised, with a 
Table 1 Sunghir individuals. Content of the bone tissue mineral part

\begin{tabular}{c|c|c|c|c|c|c|c|c|c}
\hline Sample & Minerals (\%) & $\mathrm{Ca}(\%)$ & $\mathrm{Cu}(\mathrm{ppm})$ & $\mathrm{Zn}(\mathrm{ppm})$ & $\mathrm{Pb}(\mathrm{ppm})$ & $\mathrm{Cd}(\mathrm{ppm})$ & $\mathrm{Ni}(\mathrm{ppm})$ & $\mathrm{Co}(\mathrm{ppm})$ & $\mathrm{Sr}(\mathrm{ppm})$ \\
\hline $\mathrm{C}-1$ & 71.84 & 25.46 & 5.34 & 115.34 & 0.53 & 0.16 & 8.54 & 1.92 & 43.75 \\
$\mathrm{C}-2$ & 81.23 & 28.22 & 130.9 & 81.13 & 0.71 & 0.14 & 8.54 & 1.00 \\
$\mathrm{C}-3$ & 83.09 & 41.42 & 5.02 & 101.67 & 1.25 & 0.10 & 13.84 & 3.26 & 52.13 \\
$\mathrm{C}-4$ & 68.85 & 21.75 & 0.96 & 89.13 & 0.72 & 0.05 & 0.48 & 0.34 & 37.34 \\
\hline
\end{tabular}

lower calcium level (Table 1). Trace element concentration values point to a very large proportion of terrestrial vertebrate meat in the diet. All other food components were insignificant. However, low concentration values of all elements give some reason to suggest that during the final years of his life the individual was starving or systematically undernourished. The differences in other element concentrations values also allow the assumption that the individual lived in geochemical conditions very different from those of the Sunghir people (Kozlovskaya, 2000b).

The results of the chemical analysis of the Sunghirian samples show moderate values of the concentrations. One can suppose that the vital concentration of the calcium was not high. The individual $\mathrm{C}-3$ is an exception. Her calcium bone concentration is higher than the normal value. Paleopathological investigation shows an original early-age metabolic disturbance. This pathological condition was successfully overcome during the years following (Buzhilova, 2000). Low concentration of the elements in the food and water or impossibility of assimilation of these substances can initiate calcium-phosphorus deficiency in the organism.

The specific situation was formed during the Mesolithic period in the northern territories of the modern European part of Russia. The rich forests and big lakes were very productive perspective for the Early Holocene hunters and fishers.

In 1993, a stratified burial ground, Minino I, on the coast of Lake Kubenskoe (Vologda city region), was discovered. Archaeological finds indicate the late Mesolithic age of these burials. Results of analysis (Table 2) demonstrate individual variation of diet, as in the Scandinavian Mesolithical burials (Lummelunda, Stockholm) ( Liden, 1995).

However, in neither skeleton from Minino I was the concentration of $\mathrm{Zn}$ high enough to conclude that people specialized in a fish diet. Rather, the diet was likely of mixed type and included the meat of land mammals and plants, perhaps with mollusks or insects, too. Regrettably, only one female skeleton was analyzed, making it impossible to evaluate gender patterns in diet. The largest components of diet in Minino I were plants and meat. This is paralleled by materials from the Late Mesolithic cemetery at Oleny Ostrov (Onezhskoe lake). Jakobs (1995) attempted to separate its burials on the basis of the degree of social status. He evaluated the correlations between this criterion, on the one hand, and robusticity, health status, and diet, on the other. Diet was assessed using the content of strontium. The richest graves contained skeletons with the lowest amount of strontium, so
Table 2 Trace element concentrations in human bone samples from Minino I (ppm)

\begin{tabular}{r|c|c|r|r|r}
\hline Sample & Age & Sex & Zn & Cu & \multicolumn{1}{c}{ Sr } \\
\hline 3 & $30-39$ & $\mathrm{M}$ & 86.48 & 3.16 & 46.12 \\
4 & $25-35$ & $\mathrm{M}$ & 71.76 & 1.38 & 88.32 \\
5 & $20-29$ & $\mathrm{M}$ & 86.61 & 3.38 & 40.14 \\
10 & about 50 & $\mathrm{M}$ & 105.31 & 8.70 & 113.14 \\
11 & $30-39$ & $\mathrm{M}$ & 81.46 & 2.02 & 53.12 \\
13 & $25-35$ & $\mathrm{M}$ & 72.94 & 2.67 & 56.65 \\
15 & $35-45$ & $\mathrm{M}$ & 142.83 & 2.91 & 50.80 \\
16 & $35-45$ & $\mathrm{M}$ & 113.46 & 3.69 & 71.73 \\
17 & $35-45$ & $\mathrm{M}$ & 107.04 & 8.42 & 59.96 \\
$19 / 2$ & $20-25$ & $\mathrm{~F}$ & 125.85 & 5.72 & 77.94 \\
$19 / 3$ & about 18 & $\mathrm{M}$ & 126.94 & 4.85 & 51.14 \\
\hline
\end{tabular}

Table 3 Trace element concentrations of the bone samples from the Ivanovskoe-VII site (ppm)

\begin{tabular}{l|c|c|c|c|c}
\hline \multicolumn{1}{c|}{ Sample } & Sex & Age & $\mathrm{Cu}$ & $\mathrm{Zn}$ & $\mathrm{Sr}$ \\
\hline $\begin{array}{l}\text { Iv-VII, cultural layer, } \\
\text { cranium }\end{array}$ & $\mathrm{M}$ & $30-40$ & 2.44 & 164.27 & 69.09 \\
Iv-VII , animal bone & & - & 1.71 & 210.01 & 116.59 \\
Iv-VII -VII, П.5 & $\mathrm{F}$ & About 20 & 6.05 & 237.99 & 63.59 \\
Iv-VII -VII IIa & $\mathrm{F}$ & $?$ & 3.81 & 55.65 & 74.11 \\
Iv-VII Iv-VII, П.2 & $\mathrm{M}$ & $?$ & 6.17 & 306.54 & 55.55 \\
\hline
\end{tabular}

these people must have consumed less plant food.

As our results have demonstrated, foraging populations inhabiting the lacustrine areas of northwest Russia did not focus on water resources, as did shallow-water coast dwellers of the Pacific and Atlantic Oceans. Rather, their diet was comparable to that of the people of Mesolithic Kunda and inland areas of Sweden. This may be due to cultural affinities, but also to ecological factors.

Anthropological materials of Neolithic and Chalcolithic archaeologolical cultures from the European Russia forest zone were investigated, too (Kozlovskaya, 2002).

1. The Ivanovskoe VII site is situated near the Pereslavl'Zalessky sity. It was discovered by D.A. Krainov in 1973 and excavated during several field seasons. Anthropological materials come from the Neolithic part of this site (Lyalova archaeological culture). The results of the atomic-absorption analysis of five samples of bone were examined. Concentrations of cooper, zinc, and strontium were evaluated (Table 3).

All these elements have been traditionally used for diet 
Table 4 Diachronic trends in concentrations of elements in human samples from Sakhtish Iia (ppm)

\begin{tabular}{lccccc}
\hline \multicolumn{1}{c}{ Culture } & Sex & $\mathrm{N}$ & $\mathrm{Sr}$ & $\mathrm{Cu}$ & $\mathrm{Zn}$ \\
\hline Lialovo, Neolith & $\mathrm{M}$ & 3 & 29.60 & 36.07 & 284.97 \\
Lialovo, Neolith & $\mathrm{F}$ & 3 & 22.85 & 30.75 & 295.85 \\
Early Volosovo, Eneolith & $\mathrm{M}$ & 5 & 38.99 & 26.43 & 391.67 \\
Early Volosovo, Eneolith & $\mathrm{F}$ & 1 & 29.99 & 18.43 & 639.67 \\
Late Volosovo, Eneolith & $\mathrm{M}$ & 9 & 30.72 & 37.60 & 348.40 \\
Late Volosovo, Eneolith & $\mathrm{F}$ & 10 & 28.98 & 27.90 & 480.45 \\
\hline
\end{tabular}

reconstruction. Although the individual variation of zinc and strontium in this small sample is very high, all individuals except the individual from burial IIa evidently consumed a great deal of the meat of land vertebrates or fish. The plant component of everyday nutrition is insignificant.

2. The results are the closest to those concerning two skeletons from the Neolithic site of Zamostye (Moscow region, near Dubna city). The concentration of zinc in the male skeleton from grave 4 is $180 \mathrm{ppm}$, and that in the female skeleton from grave 3 is $357 \mathrm{ppm}$.

3. Sakhtish-IIa cemetery materials present the NeolithicEneolithic population of forest zone. This Site was discovered by D.A. Krainov in 1986 and excavated over several years by E.L. Kostyleva and A.V. Utkin. Atomic-absorption analyses of bone samples make it possible to assess the diet of people buried in Sakhtish-IIa. The most specific features of this group are high concentrations of zinc and cooper, which is typical for the Mesolithic and Neolithic population of Scandinavia (Table 4).

The high level of these elements is due to the large amount of animal protein (fish, mammals and invertebrates) in the diet. The low concentration of strontium attests to the low share of plants in the diet. The comparison of trace element concentrations in male and female samples reveals some differences. Females exhibit higher concentrations of the zinc and lower ones of the copper. Thus we can fix the gender patterns of the nutrition of these Neolithic-Eneolithic societies. The diachronic trends are expressed, too. Later samples are characterized by a higher zinc concentration. This circumstance suggests that the role of fishing increased in these societies.

\section{Discussion}

The investigation of the nutrition of modern native populations can be useful for paleodiet reconstruction. The proportion of the main nutritional components (fat-proteincarbohydrate) is determined by minimal energy necessities. A population living at a high latitude or in cold temperature regions needs food rich in calories and animal proteins. Populations from the temperate climate regions use a mixed protein-carbohydrate diet. The mineral substances play a vital part in an organism's functions. Sodium, calcium, magnesium, chlorine, fluorine, zinc, copper, and iron can be considered as the most significant for cell biology and physiological functions. Traditional diets of the modern hunter-gatherers include sufficient amounts of these elements, which can be initiated by the local geochemical characteristics.

The D-group of vitamins regulates an organism's calcium absorption. A mammal's liver, eggs, and cod-liver oil contain the highest concentration of vitamin D. Physiologically active D-vitamins are synthesized by cutis. Ultra-violet rays initiate this synthesis. The D-vitamin synthesis is more successful in light-skinned persons. The statistical value of the morbidity demonstrates that the frequency of rickets is higher among dark-skinned humans than the light-skinned inhabitants of Europe (Jablonsky and Chaplin, 2000). The hypothesis of an intensive process of depigmentation among high latitude Europeans has been formulated of Jablonsky and Chaplin (Jablonsky and Chaplin, 2000). The phenomenon of the migrants' depigmentation during the last glacial transgression can de considered as evidence of the selective significance of the new status of organism mineral metabolism. Based on this data, we can presuppose the rich D-vitamin diet of the high latitude European populations. Sunghir's inhabitants had occupied the most northern part of the ancient human natural habitat. Pathology related to D-vitamin or calcium deficiency existed during juvenile age (C-1) and was overcome in adult age (Buzhilova, 2000). D-vitamin deficiency was described for the Peruvian highland infant part of the population (Frisancho, 1966). The author accentuates intensive insulation and the absence D-vitamin deficiency among the adult part of the population. C-vitamin deficiency traces were not discovered among Sunghir's individuals. As is well known, this vitamin is contained in fresh plants. The human organism may keep Cvitamin in reserve amounts for a short time.

According to information gathered it is possible to consider the Sunghir inhabitants' nutrition patterns. The results of chemical analysis show different food resources: mammal and fish meat, plants, invertebrates. Mammals were the main part of their nutrition. Two individuals made use of any part of plants. One individual (C-3), probably, ate invertebrates (mollusks, insects).

Starvation, malnutrition, irregular nutrition were typically for the ancient man. Both subadult skeletons from burial 2 have different stress markers. Probably some of these were initiated by nutritional causes. Chemical data can be used for the reconstruction of malnutrition, reconstruction although it is only a hypothetical possibility. The age dynamic of trace element concentrations during adolescence is very intricate and has not been satisfactorily studied. The low concentration of the main diet-connected trace elements of the bone tissue sample from the isolated femur can be considered (hypothetically) as evidence of chronic malnutrition. Starvation was a constant concomitant of mankind throughout its history. It does not require scientific information to know that starvation is the cause of millions of human deaths and diseases at present, too.

The results of the chemical analysis demonstrate food 
diversity. It becomes apparent as different food resources and individual nutritional specializations occur. This aspect of investigation is connected with the problem of social regulation of an individual's nutritional status. As is well known, diet patterns are determined by individual social position, by ritual and cult practice in the past and at present. In ethnological investigation the practice of nutritional limitations and taboo are known. Probably, the malnutrition markers of the individuals C-2, C-3 and C-4 are provoked by these factors. The complex structure of this burial indicates the ritual meaning of this funeral. So it is possible to suggest that buried individuals had distinctive patterns. Chemical element concentrations of the $\mathrm{C}-1$ individual bone tissue indicate satisfactory food abundance during the individual's lifetime. On the archaeological data this individual was a very significant person (Bader, 1998).

The natural surroundings of the Upper Paleolithic human were very varied. Numerous publications are devoted to paleoenvironmental reconstructions of Europe during the last glacial period. Paleobotany, paleopedology, and paleozoology investigations confirm our conception of the mosaic structure of Upper Paleolithic landscapes. There were local variants from tundra to forest-steppe conditions. So local environmental reconstruction is of great importance for the recreation of nutritional structure.

The data of palaeodietological analysis of Sunghirian bone tissue gives us grounds to suppose that these people were not only hunters. The term "hunters-gatherers" is more exact. As archaeological studies have shown, the people of Sunghir site were engaged in hunting and gathering. Warm and humid periods of the Bryansk interstadial can be of advantage to the development of zoo- and phytogathering. Nevertheless, the fall in temperature and relative dehydration of the climate, as we assume occurred according to obtained results, did not lead to any principal change in nutrition strategy.

In our opinion, the main feature of Sunghirian nutrition strategy was usage of a wide range of food sources. Judging from striking individual peculiarities, different types of Sunghirian nutrition were to a considerable extent connected with their social role in the community.

Apparently, the absence of nutritional specialisation was one of the most important characteristics, ensuring the mobile lifestyle of the Upper Palaeolithic population, including people of the Sunghir site.

Perhaps the general tendency for a Holocene climate resulted in a lesser energy requirement of the human body. Thanks to that, high calorie content and the high nutritive value of food became less crucial than they were before, and the tendency for a wider exploitation of various food resources, seen already in the Upper Palaeolithic, was further developed. Two relatively new sources of protein began to be exploited on a larger scale: small fish and invertebrates. Because all these can be procured without any serious risk, they became a food source during the hardest seasons. Availability of procurable food makes life considerably easier for the least protected members of community-women and children. As a result, populations, especially those of Neolithic hunter-gatherers, increased in size.

Acknowledgments I would like to thank the excavators of the archaeological sites N.O. Bader, A.N. Sorokin, E.1. Kostileva, A.V. Utkin, M.G. Zhilin, N.A. Makarov for their kind co-operations, E.E. Kulikova and L.V. Aleshchukin for the customary help of analytical researches, and the FRDR (Russia) for a supporting grant.

\section{References}

Ambrose SH (1993) Isotopic analysis of palaeodiets: methodological and interpretive consideration. In Sandford MK ed. Investigation of ancient human tissue. Gordon and Breach Science Publishers, 59-130

Bader ON (1998) Upper Palaeolithic grave Sunghir (the burial and surrounding). Nauchniy Mir, Moscow, 271 [In Russian]

Bocherens H (1997) Isotopic biogeochemistry as a marker of Neanderthal diet. Anthrop Anzeiger 55: 101-120

Brantingham PJ (1998) Hominid-carnivore coevolution and invasion of the predatory guild. J Anthrop Archaeol 17: $327-353$

Buzhilova AP (2000) The analysis of anomalies and indicators of physiological stress in non-mature Sunghir individuals. In Alexeeva TI, Bader NO eds. Homo sungirensis. Upper Palaeolithic man: ecological and evolutionary aspects of investigation. Moscow, 302-315 [In Russian]

Foley R (1984) Hominid evolution and community ecology. Prehistoric human adaptation in biological perspective. Academic Press, London, 1-24

Francalacci P (1989) Dietary reconstruction at Arene Candide Cave (Liguria, Italy) by means of trace elements analysis. J Arch Sci 16: 109-124

Jablonsky NG, Chaplin G (2000) The evolution of human skin coloration. J Hum Evol 39: 57-106

Jakobs K (1995) Returning to Oleni' ostrov: social, economic and skeletal dimensions of boreal forest Mesolithic cemetery. J Anthrop Archaeol 14: 359-403

Kozlovskaya MV (2000a) Technical aspects of chemical analysis. In Alexeeva TI, Bader NO eds. Homo sungirensis. Upper Palaeolithic man: ecological and evolutionary aspects of investigation. Moscow, 83-84 [In Russian]

Kozlovskaya MV (2000b) Systems of nutrition in Upper Palaeolithic communities: biological and social adaptation. In Alexeeva TI, Bader NO eds. Homo sungirensis. Upper Palaeolithic man: ecological and evolutionary aspects of investigation. Moscow, 411-421

Kozlovskaya MV (2002) Nutritional systems and lifestyle of prehistoric and historic foraging populations. Archaeol Ethnol Anthropol Eurasia 11: 141-159

Liden K (1995) Prehistoric diet transition. Stockholm University, Stockholm, 3-19 
Received: March 18, 2005

Accepted: March 26, 2005

Correspondence to: Maria V. Dobrovolskaya, Lab. of Anthropology, Institute of Archaeology of Russian Academy of Sciences, Dm. Ulianova 19, Moscow 117036, Russia

Phone: +7-095-126-9479

Fax: +7-095-126-0630

e-mail: mk_pa@mail.ru 